\title{
High Efficiency SiC Terahertz Source in Mixed Tunnelling Avalanche Transit Time Mode
}

\author{
Pranati Panda, Satya Narayana Padhi, Gana Nath Dash \\ Electron Devices Group, School of Physics, Sambalpur University, Burla, India \\ Email: gndash@ieee.org
}

Received 17 October 2014; revised 19 November 2014; accepted 17 December 2014

Academic Editor: Yarub Al-Douri, University Malaysia Perlis, Malaysia

Copyright (C) 2014 by authors and Scientific Research Publishing Inc.

This work is licensed under the Creative Commons Attribution International License (CC BY). http://creativecommons.org/licenses/by/4.0/

cC) (i) Open Access

\begin{abstract}
High frequency properties of $4 \mathrm{H}-\mathrm{SiC}$ double drift region (DDR) Mixed Tunnelling Avalanche Transit Time (MITATT) diodes are studied through computer simulation method. It is interesting to observe that the efficiency of SiC (flat) DDR MITATT diode (16\%) is more than 4 times that of Si (flat) DDR MITATT diode (3.59\%). In addition, a power output of more than 15 times from the SiC MITATT diode compared to the Si MITATT diode is commendable. A reduced noise measure of $17.71 \mathrm{~dB}$ from a low-high-low (lo-hi-lo) structure compared to that of $21.5 \mathrm{~dB}$ from a flat structure of $\mathrm{SiC}$ is indicative of the favourable effect of tunnelling current on the MITATT diode performance.
\end{abstract}

\section{Keywords}

MITATT, SiC, Terahertz, Tunnelling

\section{Introduction}

Silicon-based power devices are used in a wide variety of power electronics applications. But, there is a continuous demand for higher current, higher voltage blocking capacity, higher operating temperature and improvement in terms of efficiency, size and weight. This has made us to realise the necessity of better material to replace the existing silicon technology. In this paper the authors have suggested silicon carbide, which exceeds all the limitations of the conventional silicon devices, to be used in new generation of power devices. Silicon carbide is known to be an excellent semiconductor for high-temperature and high-speed electronics [1]-[5]. This material has very high microwave conductivity and is less susceptible to radiation effect [1]. Among all solid state devices, Mixed Tunnelling Avalanche Transit Time diode has recognised itself as a powerful microwave 
device for operation at high frequency. The basic principle of operation involved in the device offers a great deal of flexibility in the choice of the base material. Yuan et al. [6] [7] and Zhao et al. [8] have reported some experimental as well as theoretical results for the first time with a 4H-SiC IMPATT (IMPact Avalanche Transit Time) oscillator operating at X and Ka band of frequencies. They have considered the DC and high-power generation aspects of the IMPATT diode. Their results show that this diode exhibits high efficiency and high power as expected, compared to Si and GaAs IMPATT diodes. Pattanaik et al. [9] have reported the results of 6H-SiCbased DDR IMPATT diode performance with respect to DC and microwave power as well as noise characteristics and have compared the results obtained with those of Si- and GaAs-based IMPATT diodes under similar operating conditions at the D-band. But, there is no report on performance of SiC Mixed Tunnelling Avalanche Transit Time diode in the THz range except that in [5]. The report at [5] considers only noise behaviour and uses an approximate analytical technique. To improve upon the same we have used here an accurate simulation method for the study of the SiC MITATT diodes. We have obtained excellent results from the simulation, in terms of efficiency and power output as compared to those of a Si-based MITATT diode.

\section{Material Parameters of SiC}

When a semiconductor is to be used in a power source device the important material parameters which should be considered include the band gap energy, maximum electric field, electron mobility, hole mobility, saturation velocity and thermal conductivity. The values of these parameters for Si and $\mathrm{SiC}$ are listed in Table 1 . The various properties of silicon carbide such as wider band gap, larger critical electric field and higher thermal conductivity let the $\mathrm{SiC}$ devices operate at higher temperature and higher voltages offering higher power density and higher current density than the pure silicon devices. Out of numerous poly types of $\mathrm{SiC}$ only $4 \mathrm{H}-\mathrm{SiC}$ and $6 \mathrm{H}-\mathrm{SiC}$ substrates are commercially available. $4 \mathrm{H}-\mathrm{SiC}$ is the most widely explored material [10]-[13] for high power devices because its carrier mobility is higher as compared to $6 \mathrm{H}-\mathrm{SiC}$. More isotropic nature of electrical properties makes $4 \mathrm{H}-\mathrm{SiC}$ still more attractive for power device applications [5].

\section{Simulation Method}

To study the high frequency behaviour of a silicon carbide DDR MITATT diode, a one dimensional model with a doping distribution of the form $\mathrm{n}^{+} \mathrm{npp}^{+}$is taken into consideration. The schematic of the MITATT diode considered is shown in Figure 1. The diodes are first designed following a MITATT mode DC simulation scheme de-

Table 1. Some material parameters of silicon and silicon carbide.

\begin{tabular}{|c|c|c|}
\hline \multirow{2}{*}{ Properties } & \multicolumn{2}{|c|}{ Material } \\
\hline & Silicon & 4H-Silicon Carbide \\
\hline Band gap energy (eV) & 1.1 & 3.260 \\
\hline Max. electric field (MV/m) & 41.0 & 300.000 \\
\hline Electron mobility (m²/V sec) & 0.145 & 0.090 \\
\hline Hole mobility ( $\left.\mathrm{m}^{2} / \mathrm{V} \mathrm{sec}\right)$ & 0.0480 & 0.012 \\
\hline Saturation velocity $\left(10^{5} \mathrm{~m} / \mathrm{sec}\right)$ & 0.86 & 2.000 \\
\hline Thermal conductivity (W/m K) & 150.00 & 500.000 \\
\hline
\end{tabular}

\begin{tabular}{|c|c|c|c|c|}
\hline $\mathbf{n}^{+}$ & $\mathrm{n}$ & & $\mathrm{p}$ & $\mathrm{p}^{+}$ \\
\hline $\begin{array}{c}\text { End } \\
\text { region }\end{array}$ & Drift Region & $\begin{array}{c}\text { Generation } \\
\text { Region }\end{array}$ & Drift Region & $\begin{array}{c}\text { End } \\
\text { region }\end{array}$ \\
\hline
\end{tabular}

Figure 1. Schematic diagram of MITATT diode. 
veloped by Dash et al. [14]. The DC analysis also fixes the edges of the diode active layer and determines the DC electric field and carrier current profiles. The DC field profile is used to determine the percentage of tunnelling current by integrating the electron tunnelling generation rate of the form

$$
g_{T_{n}}=A_{T} E^{2}(x) \exp \left[-\frac{B_{T}}{E(x)}\right]
$$

(for a definition of the symbols refer to Appendix).

The tunnelling generation rate for holes is computed using a simulated energy band diagram [14]. The values of constants $A_{T}$ and $B_{T}$ are taken from [15]. The high frequency analysis of the diode is carried out using a small signal simulation method described in [14]. The noise behaviour of MITATT device is computed using MITATT mode noise simulation scheme developed by Dash et al. [16]. For this, the diode generation region is treated as consisting of a discrete number of noise generating sources $\left(x^{\prime}\right)$. The process of impact ionization occurring at different regions contributes to the noise owing to the random nature of the impact ionisation process. A noise source located at $x^{\prime}$ generates a noise electric field $e\left(x, x^{\prime}\right)$ at every point in the depletion layer of the diode. The terminal voltage produced by the noise source located at $x^{\prime}$ is given by

$$
V_{t}\left(x^{\prime}\right)=\int_{0}^{w} e\left(x, x^{\prime}\right) \mathrm{d} x
$$

From which the transfer impedance can be determined as

$$
Z_{t}\left(x^{\prime}\right)=\frac{V_{t}\left(x^{\prime}\right)}{I_{n}\left(x^{\prime}\right)}
$$

where the current generated in a space step $\mathrm{d} x^{\prime}$ around $x^{\prime}$ is

$$
\mathrm{d} I_{n}\left(x^{\prime}\right)=q \gamma\left(x^{\prime}\right) A \mathrm{~d} x^{\prime}
$$

Finally, the mean square noise voltage and noise measure (NM) are calculated using the relations [16]

$$
\left\langle v^{2}\right\rangle=2 q^{2} \mathrm{~d} f A \int\left|Z_{t}\left(x^{\prime}\right)\right|^{2} \gamma\left(x^{\prime}\right) \mathrm{d} x^{\prime}
$$

and

$$
\mathrm{NM}=\frac{\left\langle v^{2}\right\rangle / \mathrm{d} f}{4 k_{B} T\left(-Z_{R}\right)}
$$

The noise electric field $e\left(x, x^{\prime}\right)$ for a given location of the noise source $\gamma\left(x^{\prime}\right)$ is computed by solving the following differential equations [16],

$$
\left[D^{2}-k^{2}+\left(\alpha_{n}-\alpha_{p}+2 r_{n} k\right) D+2 \bar{\alpha} k-H-\frac{q r_{p}}{\bar{v} \in}\left(g_{T_{n}}^{\prime}+g_{T_{p}}^{\prime}\right)\right] e\left(x, x^{\prime}\right)=\frac{1}{\bar{v} \in}\left[2 q r_{p} \gamma\left(x^{\prime}\right)\right]
$$

where

$$
\begin{gathered}
H=\left(\alpha_{p}^{\prime}-\alpha_{n}^{\prime}\right) D E_{0}+\frac{2 \bar{\alpha}^{\prime} J_{0}}{\bar{v} \epsilon}, \quad k=\frac{1}{\bar{v}} \frac{\partial}{\partial t}, \quad \bar{v}=\left(v_{n} v_{p}\right)^{\frac{1}{2}} \\
D=\frac{\partial}{\partial x}, \quad \bar{\alpha}=\frac{\alpha_{p} v_{p}+\alpha_{n} v_{n}}{2 \bar{v}}, \quad r_{n}=\frac{v_{n}-v_{p}}{2 \bar{v}}, \quad r_{p}=\frac{v_{n}+v_{p}}{2 \bar{v}}
\end{gathered}
$$

The primes on $\alpha$ and $g$ denote their field derivatives.

The computation starts by putting the noise source at the beginning of the generation region. The noise electric field $e\left(x, x^{\prime}\right)$ corresponding to the location of the noise source is computed by solving Equation (7), from which the terminal voltage and transfer impedances are determined by using Equations (2) and (3). The noise source $\gamma$ is then shifted to the next space step and the process is repeated until $\gamma$ covers the whole generation region. Then the mean square noise voltage and noise measure are determined using Equations (5) and (6). 


\section{Results and Discussion}

We have applied the simulation method of analysis to different types of 4H-SiC MITATT DDR diode structures (flat and low-high-low) for operation at $0.5 \mathrm{THz}$. For a comparative study of the results obtained we have also considered a flat profile DDR diode based on Silicon. The total width in each of the two SiC diodes has been taken to be $296 \mathrm{~nm}$ whereas for the Silicon diode it has been taken as $104 \mathrm{~nm}$ (as width of diode taken depends upon the value of saturation drift velocity of charge carriers of the material). The doping concentration has been adjusted for an optimum punch through factor in each side as given in Table 2. The bias current density in each of the diode structures is taken to be $2.7 \times 10^{9} \mathrm{~A} / \mathrm{m}^{2}$ and the diode area $(A)$ is taken to be $10^{-10} \mathrm{~m}^{2}$ for all structures.

The dc and small signal characteristics of both the SiC DDR diodes and those of Silicon DDR diode at a frequency of $0.5 \mathrm{THz}$. are presented in Table 3. We observed that the maximum electric field for SiC MITATT (flat) is much greater as compared to Silicon MITATT (flat) diode. The breakdown voltage $\left(V_{B}\right)$ for SiC DDR diode is more than 10 times compared to that of Silicon DDR diode. This result is in accordance with the experimental results of Yuan et al. [7]. We found that SiC MITATT has much higher breakdown voltage as compared to silicon. This is due to larger band gap and greater saturation drift velocity of SiC as compared to that of $\mathrm{Si}$. As a result the power output of SiC flat profile DDR MITATT is found to be about 15 times higher than that of Silicon flat profile DDR MITATT. Again the efficiency of SiC flat profile DDR MITATT is about 4 times that of Si flat profile DDR MITATT. The efficiency of SiC MITATT has been further increased by taking lo-hi-lo type doping profile. The change in the nature of the electric field profile with change in doping pattern from flat to lo-hi-lo type may be noticed from Figure 2. The stiff rise in electric field localises the generation region and enhances the efficiency of the latter type diode. The peak negative conductance of SiC (flat) diode is found to be less than that of the Si (flat) diode (Figure 3). But, the breakdown voltage of SiC being much higher compared to that of Silicon the power output of SiC (flat) MITATT diode becomes 15 times more compared to the Si (flat) MITATT diode. Comparing the simulation result of SiC (flat) DDR MITATT diode with that of GaN (flat) DDR diode at $0.5 \mathrm{THz}$ (results not shown here) we found that the efficiency of GaN (flat) diode (20.6\%) is better than that of Si (flat) diode (3.59\%) and SiC (flat) diode (16\%). But the power output of GaN (flat) diode $(1.36 \mathrm{~W})$ is nearly 2.5 times than that of Si diode $(0.529 \mathrm{~W})$ and nearly one sixth that of SiC (flat)

Table 2. Design Parameters of the Si and 4H-SiC MITATT diodes considered in this paper.

\begin{tabular}{|c|c|c|c|c|c|c|c|c|c|c|c|c|}
\hline \multirow{3}{*}{ Structures } & \multicolumn{6}{|c|}{ Widths (nm) } & \multicolumn{6}{|c|}{ Doping Concentrations $\left(\times 10^{24} \mathrm{~m}^{-3}\right)$} \\
\hline & \multicolumn{3}{|c|}{ n-side } & \multicolumn{3}{|c|}{ p-side } & \multicolumn{3}{|c|}{ n-side } & \multicolumn{3}{|c|}{ p-side } \\
\hline & low & high & low & low & high & low & low & high & low & low & high & low \\
\hline Si (flat) & - & - & 52 & 52 & - & - & - & - & 1.4 & 1.4 & - & - \\
\hline SiC (flat) & - & - & 148 & 148 & - & - & - & - & 1.94 & 1.94 & - & - \\
\hline SiC (lo-hi-lo) & 104 & 22 & 22 & 22 & 22 & 104 & 1.6 & 5.0 & 1.6 & 1.6 & 5.0 & 1.6 \\
\hline
\end{tabular}

Table 3. Microwave properties of Si and 4H-SiC MITATT diodes at $J_{0}=2.7 \times 10^{9} \mathrm{~A} / \mathrm{m}^{2}$ and design frequency of $0.5 \mathrm{THz}$.

\begin{tabular}{|c|c|c|c|}
\hline \multirow{2}{*}{ Properties } & \multicolumn{3}{|c|}{ Structures } \\
\hline & Si (flat) & SiC (flat) & SiC (lo-hi-lo) \\
\hline$E_{0}\left(\times 10^{8} \mathrm{~V} / \mathrm{m}\right)$ & 1.225 & 5.7875 & 6.01 \\
\hline$V_{B}(\mathrm{~V})$ & 8.42 & 90.8 & 90.0 \\
\hline$\eta \quad(\%)$ & 3.59 & 16.0 & 17.5 \\
\hline$-G_{p}\left(\times 10^{7} \mathrm{~S} / \mathrm{m}^{2}\right)$ & 29.9 & 7.73 & 7.94 \\
\hline$-Z_{R}\left(\times 10^{-11} \mathrm{~m}^{2}\right)$ & 2.49 & 4.94 & 3.87 \\
\hline$P_{\mathrm{RF}}(\mathrm{W})$ & 0.529 & 7.96 & 8.03 \\
\hline$J_{T} / J_{0} \quad(\%)$ & 26.98 & 24 & 31.67 \\
\hline
\end{tabular}




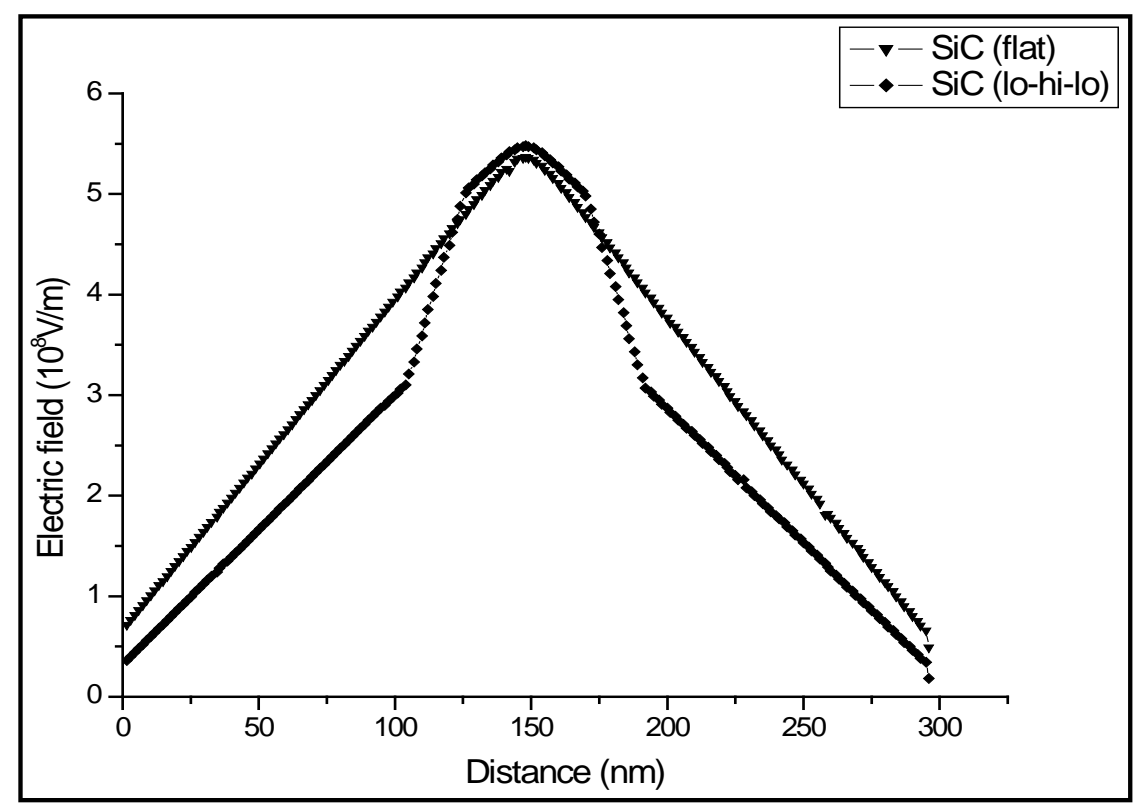

Figure 2. Electric field profile of SiC (flat) and SiC (lo-hi-lo) DDR MITATT diodes.

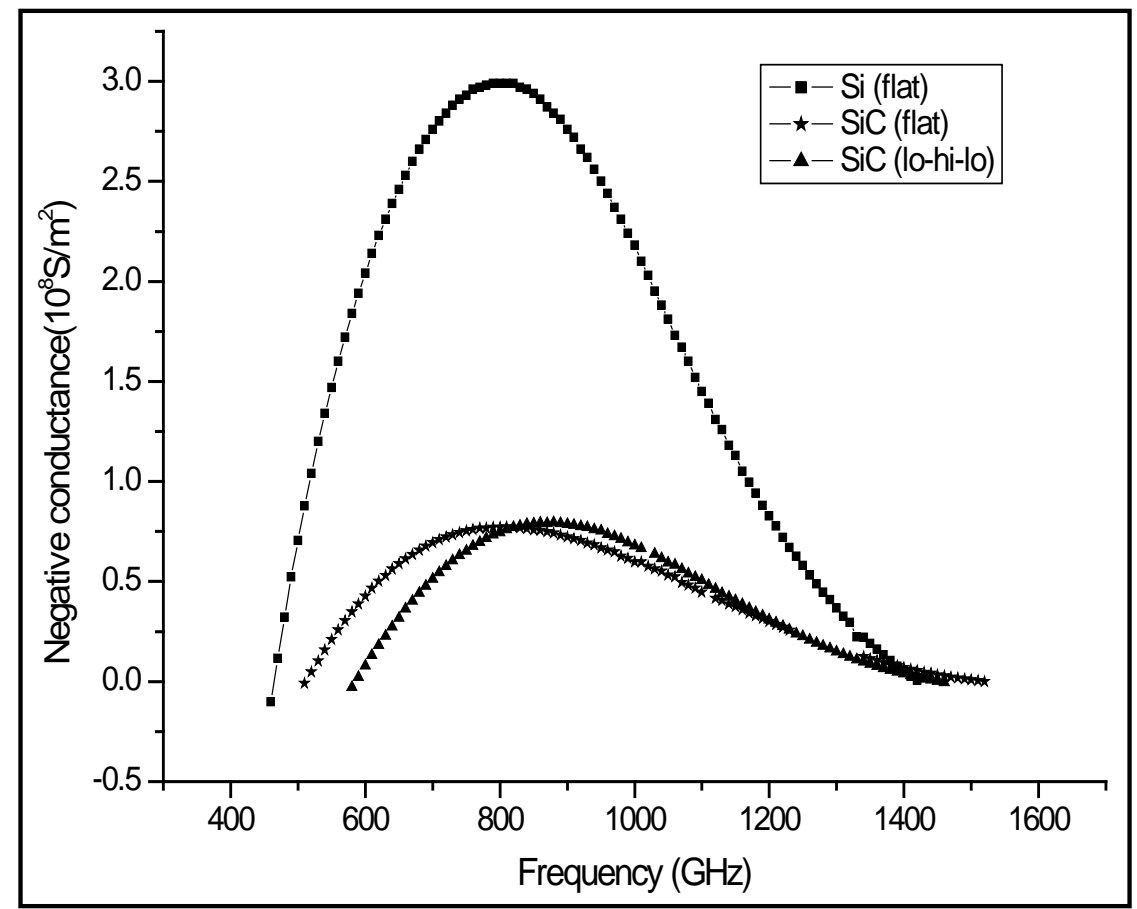

Figure 3. Variation of device negative conductance as a function of frequency for $\mathrm{Si}$ (flat), SiC (flat) and SiC (lo-hi-lo) MITATT diodes.

diode (7.96 W). Thus, from the above properties, it can be observed that $\mathrm{SiC}$ is a much superior material compared to $\mathrm{Si}$ and $\mathrm{GaN}$ as a terahertz source operating in MITATT mode.

In MITATT diodes avalanching is a noisy process while tunnelling is a quiet process. The percentage of tunnelling current in a MITATT diode can be increased either by increasing the junction field with a suitable structural modification or by decreasing the operating bias current density. We have varied the structure of diode to study the noise in SiC MITATT at $0.5 \mathrm{THz}$ operating frequency. We have computed the mean square noise voltage in each case. We found that as the percentage of tunnelling current increases the height of the noise 
spike decreases. Figure 4 shows this effect very clearly. The value of noise measure gives the value of noise to power ratio. The values of minimum NM is found to be $12.71 \mathrm{~dB}$ (at $0.98 \mathrm{THz}$ ), $21.50 \mathrm{~dB}$ (at $1.25 \mathrm{THz}$ ) and $17.71 \mathrm{~dB}$ (at $1.3 \mathrm{THz}$ ) for the Si (flat), SiC (flat) and SiC (lo-hi-lo) MITATT diode respectively. Figure 5 shows the plots of NM with frequency. The lowest value of NM for $\mathrm{SiC}$ is found to decrease with increase in tunnelling current. This is due to decrease in percentage of avalanche component of current. The minimum NM value is found to be $27.2 \mathrm{~dB}$ (at $0.71 \mathrm{THz}$ ) for GaN (flat) diode. The noise measure value of GaN (flat) diode is much higher as compared to $\mathrm{Si}$ (flat) and $\mathrm{SiC}$ (flat) diodes. This is due to very small value of percentage of tunnelling current (3.85\%) in case of GaN (flat) diode which renders it operate in nearly IMPATT mode where noise is generally higher.

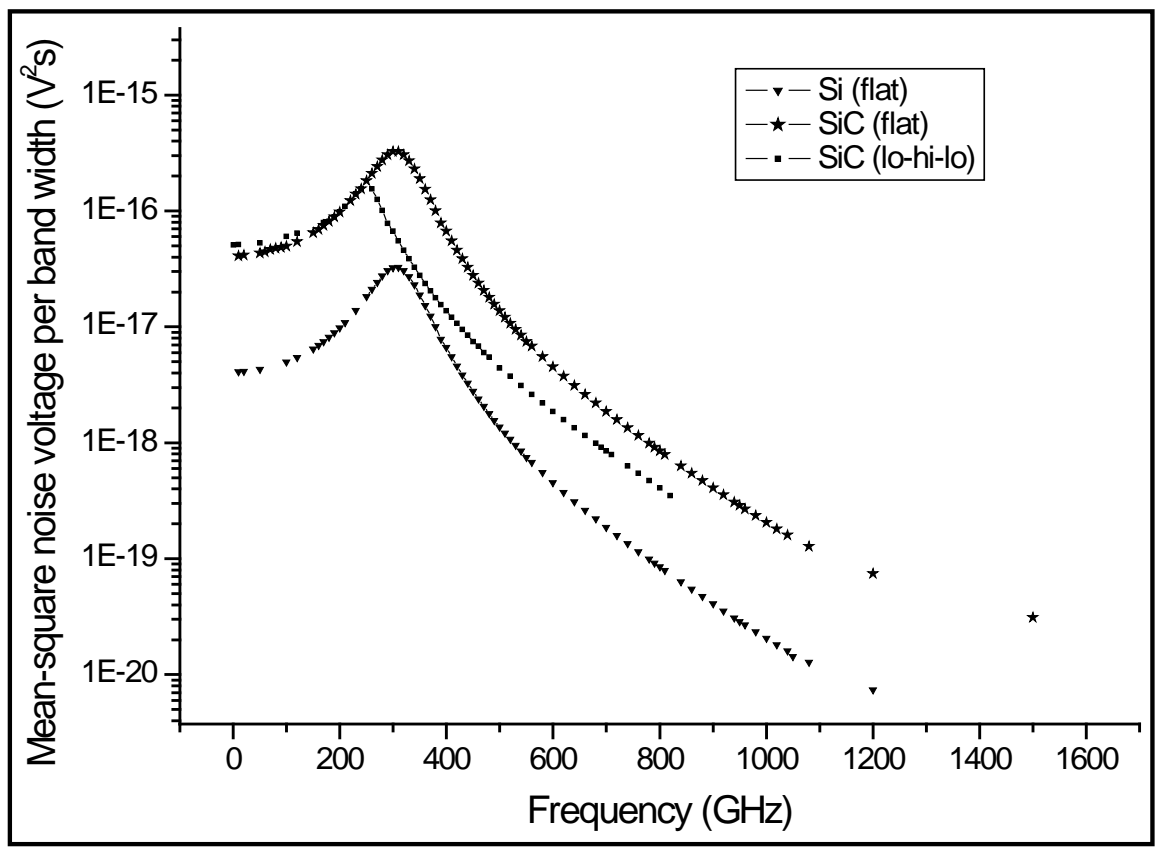

Figure 4. Mean-square noise voltage per band width versus frequency of Si (flat), SiC (flat) and SiC (lo-hi-lo) MITATT diodes.

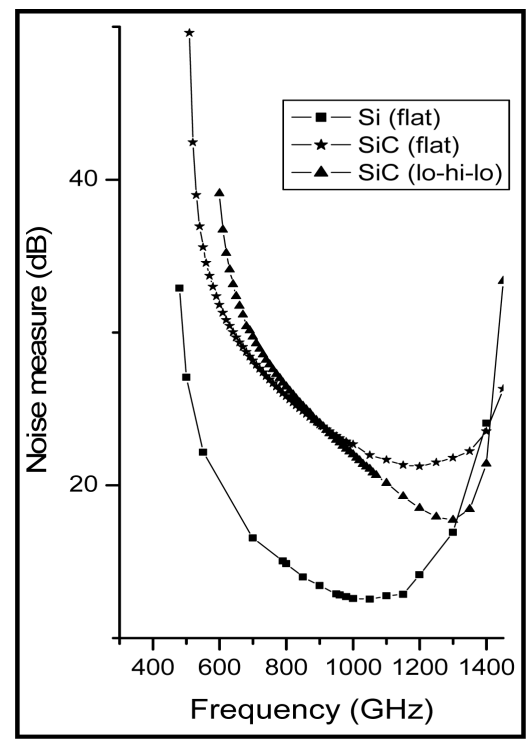

Figure 5. Noise measure versus frequency for Si (flat), SiC (flat), SiC (lo-hi-lo) MITATT diodes. 


\section{Conclusion}

Mixed mode analysis of 4H-SiC MITATT diodes has been carried out. The paper, while establishing the superior performance of $4 \mathrm{H}-\mathrm{SiC}$ over $\mathrm{Si}$, unveils some interesting properties of mixed mode operation. DC to microwave conversion efficiency of $17.5 \%$ from the SiC lo-hi-lo MITATT diode is noteworthy. The advantage of mixed mode operation is clearly demonstrated in the tunnelling-assisted noise reduction from $21.5 \mathrm{~dB}$ (SiC flat) to $17.7 \mathrm{~dB}$ (SiC lo-hi-lo). Thus, we conclude that $4 \mathrm{H}-\mathrm{SiC}$ has a great potential for application as a MITATT diode even at the terahertz frequency.

\section{References}

[1] Brezeanu, G. (2007) High Performance Power Diodes on Silicon Carbide and Diamond: The Publishing House of the Romania Academy, 8, 1-14.

[2] Singh, K., Cooper, J.A., Meloch, M.R., Chow, T.P. and Palmour, J.W. (2004) Silicon Carbide Power Schoottky and Pin Diodes. IEEE Transactions on Electron Devices, 49, 665-672. http://dx.doi.org/10.1109/16.992877

[3] Traplee, M.C., Madangagly, V.P., Zhang, Q. and Surdarsan, T.S. (2001) Design Rules for Field Pate Edge Termination in SiC Schottky Diodes. IEEE Transactions on Electron Devices, 48, 2659-2664. http://dx.doi.org/10.1109/16.974686

[4] Sheridan, D.C., Niu, G., Merrett, J.N., Cresller, J.D., Ellis, C. and Tin, C.C. (2000) Design and Fabrication of Planar Guard Ring Termination for High Voltage Silicon Carbide Diodes. Solid-State Electronics, 44, 1367-1372. http://dx.doi.org/10.1016/S0038-1101(00)00081-2

[5] Karan, D.K., Panda, P. and Dash, G.N. (2013) Effect of Tunneling Current on Noise Characteristics of a 4H-SiC Read Avalanche Diode. Journal of Semiconductors, 34, Article ID: 014001. http://dx.doi.org/10.1088/1674-4926/34/1/014001

[6] Luo, Y., Melloch, M.R., Cooper, J.A. and Webb, K.J. (2000) Silicon Carbide IMPATT Oscillator for High-Power Microwave and Millimeter-Wave Generation. IEEE/Cornell Conference on High Performance Devices, Ithaca, 7-9 August 2000, 158-167. http://dx.doi.org/10.1109/CORNEL.2000.902533

[7] Yuan, L., Melloch, M.R., Cooper, J.A. and Webb, K.J. (2001) Experimental Demonstration of a Silicon Carbide IMPATT Oscillator. IEEE Electron Device Letters, 22, 266-268. http://dx.doi.org/10.1109/55.924837

[8] Zhao, J.H., et al. (2000) Monte Carlo Simulation of 4H-SiC IMPATT Diodes. Semiconductor Science and Technology, 15, 1093-1100. http://dx.doi.org/10.1088/0268-1242/15/11/314

[9] Pattanaik, S.R., Dash, G.N. and Mishra, J.K. (2005) Prospects of 6H-SiC for Operation as an IMPATT Diode at 140 GHz. Semiconductor Science and Technology, 20, 299-304. http://dx.doi.org/10.1088/0268-1242/20/3/008

[10] Zhang, C.X., et al. (2011) Effects of Bias on the Irradiation and Annealing Responses of 4H-SiC MOS Devices. IEEE Transactions on Nuclear Science, 58, 2925-2929. http://dx.doi.org/10.1109/TNS.2011.2168424

[11] Imhoff, E.A., et al. (2011) High Performance Smoothly Tapered Junction Termination Extensions for High Voltage 4H-SiC Devices. IEEE Transactions on Electron Devices, 58, 3395-3400. http://dx.doi.org/10.1109/TED.2011.2160948

[12] Zhang, H., Tolbert, L.M. and Ozpinec, B. (2011) Impact of SiC Devices on Hybrid Electric and Plug-In Hybrid Electric Vehicles. IEEE Transactions on Industry Applications, 47, 912-921. http://dx.doi.org/10.1109/TIA.2010.2102734

[13] Panda, A.K. and Rao, V.M. (2009) Modeling and Comparative Study on the High Frequency and Noise Characteristics of Different Polytypes of SiC Based IMPATTs. IEEE Asia Pacific Microwave Conference, Singapore, 7-10 December 2009, 1569-1572. http://dx.doi.org/10.1109/APMC.2009.5384396

[14] Dash, G.N. and Pati, S.P. (1992) A Generalized Simulation Method for MITATT Mode Operation and Studies on the Influence of Tunnel Current on IMPATT Properties. Semiconductor Science and Technology, 7, 222-230. http://dx.doi.org/10.1088/0268-1242/7/2/008

[15] Sze, S.M. (1987) Physics of Semiconductor Devices. 2nd Edition, John Wiley \& Sons, New York.

[16] Dash, G.N., Mishra, J.K. and Panda, A.K. (1996) Noise in Mixed Tunneling Avalanche Transit Time Diode. SolidState Electronics, 39, 1473-1479. http://dx.doi.org/10.1016/0038-1101(96)00054-8 


\section{Appendix: Definitions of Symbols}

$A$ : area of the diode

$E(x)$ : electric field at $x$

$E_{0}$ : maximum electric field

$e\left(x, x^{\prime}\right)$ : noise electric field at $x$ due to noise source at $x^{\prime}$

$\mathrm{d} f$ : frequency interval

$G_{p}$ : peak value of diode conductance

$g_{T_{n}}$ : tunnelling generation rate for electrons

$\mathrm{d} I_{n}\left(x^{\prime}\right)$ : current generated in a space step $\mathrm{d} x^{\prime}$

$J_{T}$ : tunnelling current density

$J_{0}$ : total current density

$k_{B}$ : Boltzmann constant

NM: noise measure

$P_{\mathrm{RF}}:$ RF power output

$q$ : electronic charge

$T$ : absolute temperature

$V_{B}$ : breakdown voltage

$v_{n}$ : drift velocity for electrons

$v_{p}$ : drift velocity for holes

$\left\langle v^{p}\right\rangle$ : mean-square noise voltage

$V_{t}$ : terminal voltage caused by noise source $\gamma\left(x^{\prime}\right)$

$W$ : width of the depletion layer

$x$ : general symbol to define distance in active layer

$x^{\prime}$ : position of the noise element

$Z_{R}$ : real part of device negative resistivity

$Z_{t}$ : transfer impedence

$\alpha_{n}$ : ionisation rate for electrons

$\alpha_{p}$ : ionisation rate for holes

$\epsilon$ : permittivity of the semiconductor

$\gamma$ : noise generation rate 
Scientific Research Publishing (SCIRP) is one of the largest Open Access journal publishers. It is currently publishing more than 200 open access, online, peer-reviewed journals covering a wide range of academic disciplines. SCIRP serves the worldwide academic communities and contributes to the progress and application of science with its publication.

Other selected journals from SCIRP are listed as below. Submit your manuscript to us via either submit@scirp.org or Online Submission Portal.
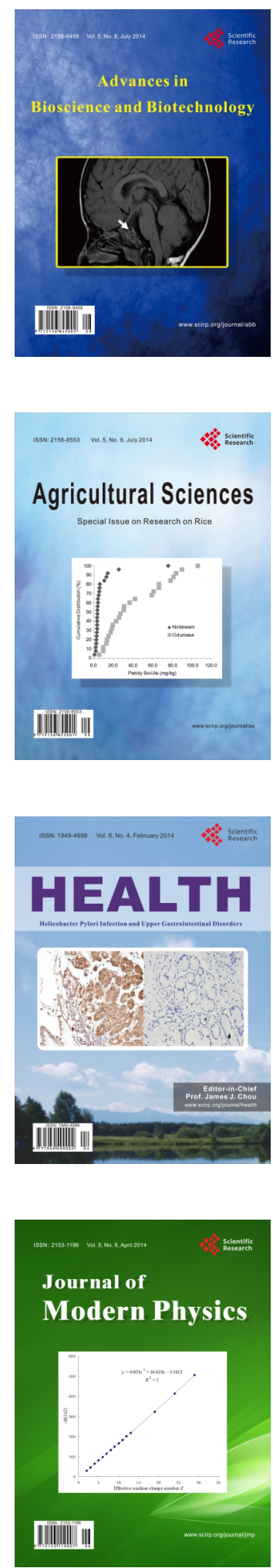
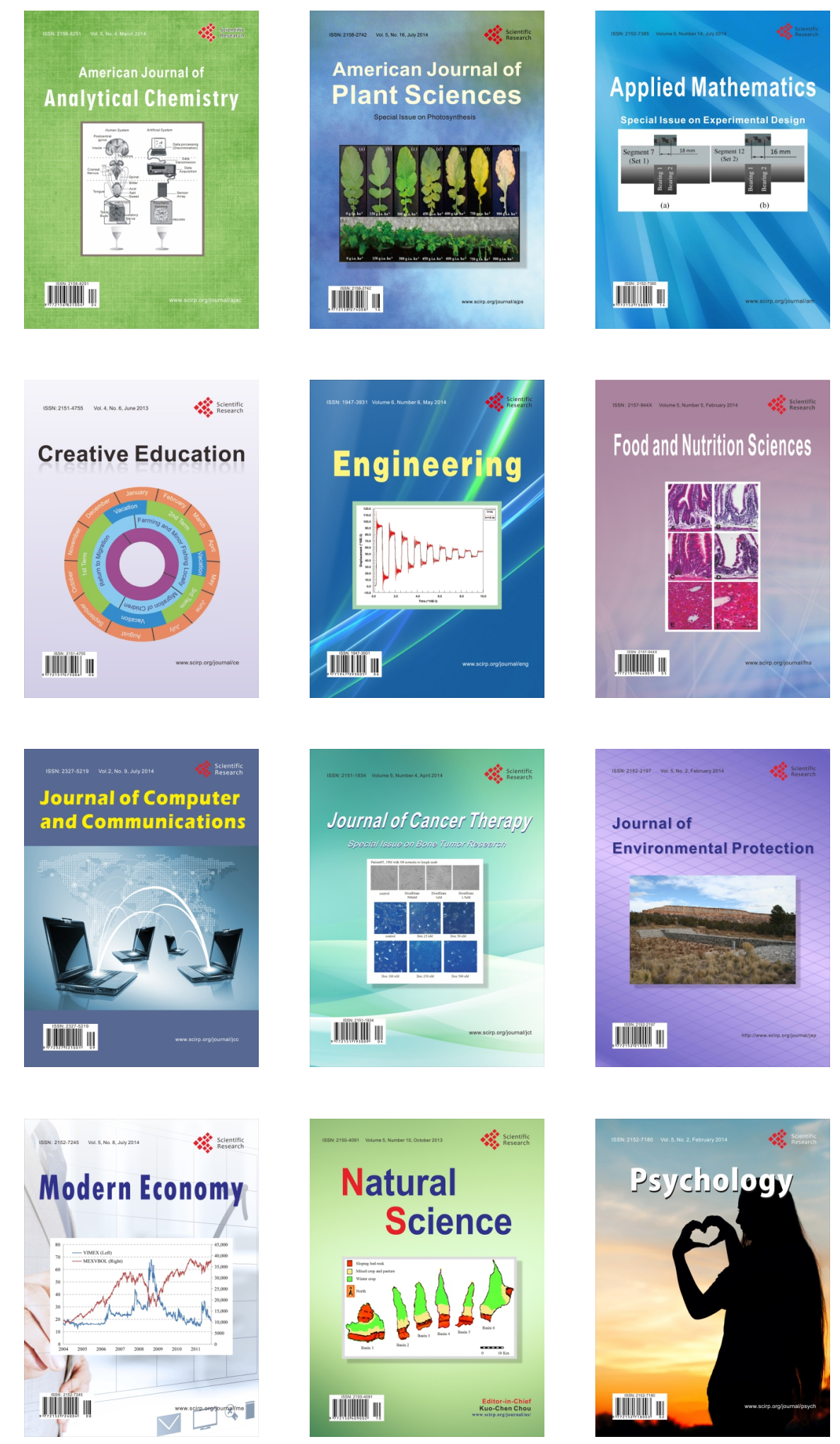